'Fundação Oswaldo Cruz (Fiocruz) - Rio de Janeiro (RJ), Brasil.

leticiatbs@gmail.com

${ }^{2}$ Centro de Atenção Psicossocial Carlos Augusto Magal (CapsMagal) - Rio de Janeiro (RJ), Brasil.

\section{Eu quero entrar na rede: análise de uma experiência de inclusão digital com usuários do Caps}

\author{
I want to join the network: analysis of a digital inclusion experience \\ with Psychosocial Care Center users
}

André Pereira Neto', Bruna Dantas Ribeiro', Ana Paula Freitas Guljor', Leticia Barbosa', Christiane Moema Alves Sampaio ${ }^{2}$, Carolina Aires de Castro², Paulo Amarante ${ }^{\mathbf{1}}$

DOI: 10.1590/0103-11042020E307

RESUMO As transformações ocorridas mundialmente, nos padrões de interrelações sociais pela ampliação do acesso à internet, colocam a inclusão digital como uma estratégia potente no processo de desinstitucionalização do sujeito em sofrimento psíquico. O objetivo deste artigo foi apresentar e analisar uma experiência de inclusão digital que envolveu dez usuários do Centro de Atenção Psicossocial Carlos Augusto da Silva Magal, em Manguinhos, na cidade do Rio de Janeiro. As atividades desenvolvidas foram fruto de decisões tomadas coletivamente a partir da troca de experiência e opiniões entre todos os participantes. Os usuários foram protagonistas na construção do blog Libertando a Mente que se transformou em um ambiente de articulação e espaço de fala para esses usuários, favorecendo a desconstrução de preconceitos. Essa experiência de inclusão digital promoveu a interlocução das vivências dos usuários com seus familiares, moradores do território e com a sociedade. A apropriação das Novas Tecnologias de Informação e Comunicação atuou como instrumento facilitador de autonomia e visibilidade dos usuários envolvidos no projeto. Desse modo, pode ser considerada uma importante ferramenta a ser incorporada no cuidado pautado pela desinstitucionalização, diretriz estruturante da Reforma Psiquiátrica Brasileira.

PALAVRAS-CHAVE Internet. Inclusão digital. Saúde mental. Serviços de saúde mental. Pesquisa participativa baseada na comunidade.

\begin{abstract}
The globally transformed patterns of social interrelationships through expanded internet access set digital inclusion as a powerful strategy in deinstitutionalizing the subject with psychological distress. This paper aims to present and analyze a digital inclusion experience that involved ten users from the Carlos Augusto da Silva Magal Psychosocial Care Center, in Manguinhos, Rio de Janeiro, Brazil. The activities resulted from decisions taken collectively from the exchange of experience and opinions between all participants. Users participated in the construction of the blog Libertando a Mente (Freeing the Mind), which became an articulation and voicing environment for these users, favoring the deconstruction of prejudice. This digital inclusion experience promoted the interlocution of users' experiences with their families, territory residents, and society. The appropriation of the New Information and Communication Technologies facilitated the autonomy and visibility of the users involved in the project. Thus, it can be considered a valuable tool to be incorporated into deinstitutionalization-based care: a basic guideline of the Brazilian Psychiatric Reform.
\end{abstract}

KEYWORDS Internet. Digital inclusion. Mental health. Mental health services. Community-based participatory research. 


\section{Introdução}

Eu quero entrar na Rede Promover um debate, Juntar via internet um grupo de tietes de Connecticut. Pela Internet Gilberto Gil (1997).

Há 50 anos, era inconcebível alguém ter nas mãos um aparelho portátil que possibilitasse não apenas a comunicação entre as pessoas, mas que facilitasse os negócios e a busca por informação e conhecimento, além de dispor de outras funcionalidades'. As Novas Tecnologias de Informação e Comunicação (NTIC) são diferentes do modelo de comunicação até então predominante. As mídias massivas, como o rádio, a televisão e o jornal, caracterizam-se pelo fluxo de informação unidirecional. Nelas, são os proprietários dos meios de comunicação que decidem o que os usuários devem, ou não, saber. Com a emergência da Web 2.0 no início dos anos 2000, qualquer cidadão com acesso às mídias digitais e habilidades para utilizá-las passou a ser capaz de produzir conteúdo e compartilhá-lo globalmente a qualquer momento na internet ${ }^{2}$.

$\mathrm{O}$ advento da mobilidade barateou o acesso e aumentou o quantitativo de usuários ${ }^{\mathbf{3} 4}$. Entre 2005 e $2018^{5}$, o total de indivíduos com acesso à internet passou de 1 bilhão para 3 bilhões.

Apesar desse crescimento, os 'excluídos digitais' ainda são uma realidade. Trata-se de cidadãos que não têm condições financeiras de adquirir um dispositivo ou residem em regiões onde não há acesso à rede ou não sabem como usar, apropriar-se e tirar proveito das NTIC ${ }^{6}$. Nesse caso, os indicadores socioeconômicos continuam sendo a explicação para as diferenças no acesso à internet ${ }^{7}$. Em geral, o termo 'inclusão digital' se refere a políticas e iniciativas voltadas para abrandar esses problemas.

O presente artigo apresenta e analisa uma experiência de inclusão digital realizada com dez usuários do Centro de Atenção Psicossocial Carlos Augusto da Silva Magal (Caps-Magal) na cidade do Rio de Janeiro, utilizando as NTIC como dispositivo estratégico para a construção de protagonismo dos usuários em saúde mental.

Os Caps são os organizadores do sistema de saúde mental público e o principal dispositivo da Rede de Atenção Psicossocial (Raps) que articula diversos pontos de atenção ${ }^{8}$. Nesse contexto, são os dispositivos estruturantes do cuidado na Reforma Psiquiátrica Brasileira (RPB), responsáveis por articular projetos de vida voltados para a reabilitação psicossocial, a promoção da cidadania e da autonomia de usuários e familiares ${ }^{9}$. Desse modo, a incorporação de estratégias que possibilitem o uso e apropriação das mídias digitais por usuários das Raps pode contribuir para sua inclusão social e para sua emancipação. Pesquisas recentes, realizadas no Brasil, mostram que a população em sofrimento psíquico em tratamento em Caps é hoje composta de uma maioria de indivíduos com baixo poder econômico, baixa escolaridade e sem emprego fixo ${ }^{10}$.

O Caps-Magal se insere nesse contexto. Ele está localizado em Manguinhos, um conjunto de comunidades populares que reúne aproximadamente 42 mil habitantes. Sua criação foi fruto da luta comunitária e de profissionais da saúde atuantes no território. A Escola Nacional de Saúde Pública Sergio Arouca da Fundação Oswaldo Cruz (Ensp/Fiocruz) desenvolve, em parceria com a Secretaria Municipal de Saúde, o Projeto Teias que, entre outras ações, inclui a cobertura de $100 \%$ do território de Manguinhos pela Estratégia Saúde da Família. O Caps-Magal é um dos dispositivos de saúde do projeto.

A população que reside nessa comunidade compartilha de uma realidade caracterizada por: exclusão social, desemprego, analfabetismo, descaso governamental e violência com inúmeros confrontos armados. O rendimento domiciliar per capita é menor que um salário mínimo. Apesar das obras públicas realizadas pelos governos estadual e federal na região, os problemas com rios poluídos, bueiros entupidos, entulhos de lixo e rede de saneamento precária persistem, fazendo com que os moradores sejam expostos a condições ambientais 
e habitacionais extremamente degradantes ${ }^{11}$. Os dez participantes do projeto são moradores da região, têm baixa renda familiar e não possuem emprego formal. Eles foram selecionados pela coordenação Caps-Magal por se encontrarem em estabilidade no processo terapêutico e dominarem algumas habilidades básicas e necessárias para o uso das NTIC e para a produção de conteúdo.

Nesse sentido, uma questão norteadora deste artigo foi analisar se um ambiente virtual, construído por pessoas em sofrimento psíquico, contribuiu para a promoção da inclusão social e favoreceu a desconstrução do estigma do qual são vítimas.

A experiência foi realizada por meio da parceria entre o Laboratório Internet, Saúde e Sociedade (LaISS) vinculado ao Centro de Saúde Escola Germano Sinval de Faria, o CapsMagal e o Laboratório de Estudos e Pesquisas em Saúde Mental e Atenção Psicossocial (Laps). Essas iniciativas de pesquisa e assistência são parte integrante da Ensp/Fiocruz. A equipe multidisciplinar foi composta por profissionais da área da saúde e das ciências humanas e sociais. A experiência contou com a participação de uma mediadora. Esse projeto, realizado entre 2018 e 2019, contou com o apoio da Vice-Presidência de Educação, Informação e Comunicação em Saúde da Fiocruz.

A seguir, será feita uma apresentação do projeto 'Eu quero entrar na Rede', descrevendo os métodos adotados e alguns de seus resultados. Em seguida, serão discutidos os fatores que facilitaram e prejudicaram sua realização e os desafios para sua replicação.

\section{Metodologia}

A realização dessa experiência seguiu os parâmetros da metodologia qualitativa da 'Translação do Conhecimento': trata-se de uma proposta metodológica de construção conjunta de conhecimento que leva em consideração o saber acadêmico formal e a expertise fruto da prática e da vivência concretas ${ }^{12,13}$.
A 'Translação do Conhecimento' se desenvolve em meio a negociações constantes de interesses distintos, incertos e instáveis, que resultam na criação de um conhecimento compartilhado ${ }^{12}$. Para que o método se torne possível, são necessários três tipos de práticas, a saber: 'logísticas' (atitudes de coordenação do projeto), 'cognitivas' (sobre o conteúdo em si) e 'estratégicas' (conjunto de atividades, competências e esforços que são necessários para mobilizar os diferentes grupos e também para manter os mesmos interessados) ${ }^{\mathbf{1 2}}$. A 'Translação do Conhecimento' guarda íntima relação com os pressupostos teóricos de Paulo Freire $^{\mathbf{1 4}}$ que propõe uma abordagem pedagógica que reconhece e valoriza os saberes individuais e coletivos dos cidadãos.

Desse modo, o trabalho desenvolvido no projeto buscou valorizar os saberes dos cidadãos em sofrimento psíquico, construindo um processo de troca de conhecimentos e experiências entre profissionais, pesquisadores e usuários. Todas as atividades práticas desenvolvidas durante a realização do projeto foram fruto de decisões tomadas coletivamente a partir da troca de vivências e opiniões entre os participantes. Agindo assim, essa atividade se organizou visando incentivar o protagonismo dos participantes, pois buscou valorizar suas experiências.

Tendo como base o método e as abordagens teórica e pedagógica citadas, foram desenvolvidas atividades visando à produção de um blog. Foram realizadas palestras, rodas de conversa e exercícios práticos e teóricos. Foram priorizadas as atividades que proporcionaram maior autonomia, troca de experiência e conhecimento entre os usuários e os demais envolvidos.

Além do referencial da 'Translação do Conhecimento', o projeto contou com alguns elementos da chamada 'Pedagogia baseada em competências'15. Ela propõe que o processo ensino-aprendizagem se desloque do domínio dos conteúdos, voltando-se para as competências e habilidades a serem desenvolvidas e estimuladas no indivíduo, sobretudo aquelas 
relacionadas com a prática profissional. Assim, a lógica linear do ensino por disciplinas é subvertida, dando espaço a outra lógica de ensino-aprendizagem mais transversal e complexa ${ }^{15}$.

A atividade de inclusão digital contou com a participação de 10 usuários do Caps-Magal e teve a duração de 12 meses, de outubro de 2018 a setembro de 2019. Foram realizados 40 encontros semanais no LaISS com a mediação de uma profissional do laboratório e o acompanhamento de um profissional do Caps. Cada encontro teve a duração de 2 horas.

Os participantes foram selecionados pela equipe do Caps-Magal a partir da proposta de construção de um blog. Foram convidados usuários em fase não aguda, com boa adesão ao serviço e que tivessem o domínio básico das principais ferramentas digitais. Os 10 usuários selecionados pelos profissionais da CapsMagal receberam uma bolsa auxílio mensal de R\$ 100,00. Oito participantes eram do sexo masculino, e dois, do sexo feminino; e tinham entre 20 e 40 anos.

Todo o processo foi estruturado por uma equipe multidisciplinar, que incluiu profissionais da área da saúde e das ciências humanas e sociais do LaISS, do Caps e do Laps. A equipe se reuniu mensalmente para pensar de forma contínua e coletiva as atividades do projeto, que foram divididas em quatro etapas, a saber:

1 - Apresentação do espaço da Fiocruz e introdução teórica e crítica - 1 mês (outubro de 2018)

2 - Diagnóstico e nivelamento de competências - 2 meses (novembro e dezembro de 2018)

3 - Construção do blog - 3 meses (janeiro a março de 2019)

4 - Produção de conteúdo - 6 meses (Abril a setembro de 2019)

Durante todo o desenvolvimento do projeto, foram produzidos materiais (relatórios, cronogramas, tabelas de avaliação de competências etc.) que permitiram o registro e, consequentemente, a reprodução das atividades do projeto.

\section{Resultados}

As atividades do projeto tiveram início em outubro de 2018. Para ambientar os usuários com o campus da Fiocruz, no primeiro encontro, foi realizada uma visita pelos espaços nos quais, na maior parte do tempo, os usuários passariam a transitar: Ensp, Centro de Saúde Escola Germano Sinval de Faria (CSEGSF) e LaISS. Nos encontros seguintes, essa ambientação foi ampliada para outros locais do campus. Essas atividades favoreceram a construção de um sentimento de intimidade dos usuários com o espaço da Fiocruz. Esse processo, agregado à elaboração de um crachá para uso nos dias de atividade, facilitou a circulação dos usuários no campus e possibilitou que eles transitassem por espaços nos quais se sentiam constrangidos de circular, apesar de ser permitido ao público geral. No primeiro mês, foram realizados debates sobre a RPB, sobre a comunicação comunitária e sobre o projeto em que eles estavam começando a participar. Um dos resultados está associado a método de trabalho empregado nessa atividade.

Por meio da 'Pedagogia baseada em competências', foi constatado que se tratava de um grupo com diferentes níveis de conhecimento acerca das NTIC. Alguns apresentavam um alto domínio das ferramentas digitais, enquanto outros revelaram dificuldades nesse campo. Desse modo, foi identificada a necessidade de realizar um diagnóstico das habilidades dos participantes em relação às NTIC e um nivelamento de competências digitais que permitisse que todos participassem da produção de conteúdo para o blog. As características e o conteúdo desse nivelamento foram decididos pelos próprios participantes - reiterando assim o processo dialógico característico da ‘Translação do Conhecimento' apresentado 
anteriormente como referencial metodológico do projeto. Foram realizadas atividades de diagnóstico e nivelamento por meio de exercícios práticos, bem como trabalhos colaborativos e autocríticos, com auxílio da mediadora.

Considerando o referencial da 'Pedagogia baseada em competências', foi importante estabelecer uma escala de competências (quadro 1) e habilidades no domínio das ferramentas associadas às novas tecnologias de informação e comunicação nessa etapa do processo, da seguinte forma:

Quadro 1. Escala de competências

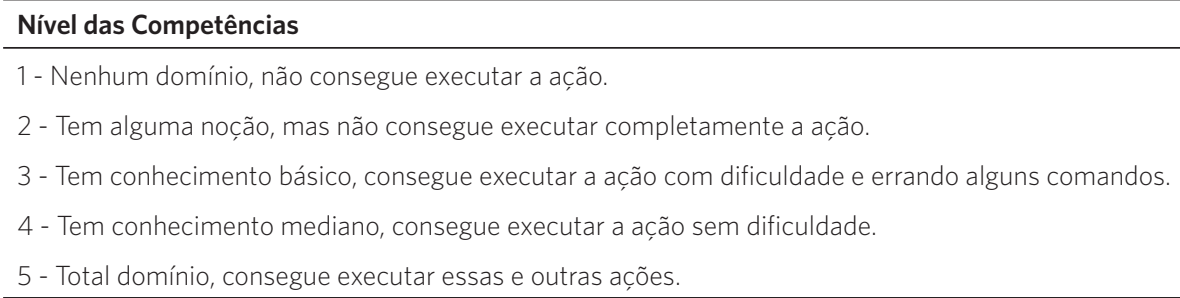

Foi construída uma ferramenta de avaliação de competências dividida em quatro partes.

Na primeira, foi avaliada a capacidade de 'produção de texto' do participante. Para tanto, foi verificado se o usuário era capaz de realizar as seguintes atividades: ligar o computador; abrir o Word ${ }^{\circledR}$; digitar o texto; criar uma pasta; salvar em um arquivo; fechar e localizar o arquivo; abrir o navegador e, em seguida, o e-mail pessoal; e enviar o arquivo produzido como anexo.

Em seguida, foi identificado o domínio em relação à ‘captura de imagem' na Web. Assim, foi avaliado se o participante deveria era capaz de abrir o navegador; pesquisar e baixar uma imagem; criar uma pasta; salvar o arquivo; e fechar e encontrar o arquivo salvo. Também foi examinado se ele conseguia abrir o navegador e, em seguida, seu e-mail, para anexar e enviar a imagem pesquisada.

A terceira competência correspondia à capacidade de 'produção de fotografia'. Para o mapeamento dessa competência, as oficinas foram realizadas com a utilização do celular dos participantes ou de uma máquina fotográfica digital, caso estivesse à disposição. Foi avaliado se o usuário conseguia executar as seguintes atividades: iniciar a câmera, focalizar e enquadrar uma cena; escolher a iluminação; fotografar; transferir as imagens produzidas para o computador por meio de cabo USB; abrir a pasta na qual a imagem estava armazenada; transferir os arquivos para o computador; anexar as fotografias a um e-mail e enviá-las.

A quarta competência englobou a habilidade de 'produção de vídeo'. Para tanto, foi averiguado se o participante tinha aptidão para produzir um texto e apresentá-lo em formato de vídeo, utilizando recursos de enquadramento, iluminação e áudio. Similar à competência referente à produção fotográfica, também foi mapeado se o usuário conseguia transferir o vídeo produzido para o computador, por meio de um cabo USB, anexá-lo a uma mensagem de e-mail e enviá-lo.

Ao aplicar a ferramenta de avaliação, foi possível identificar o domínio que cada participante tinha em relação às competências predefinidas, mencionadas acima. Assim, as múltiplas habilidades envolvidas em cada oficina foram individualmente pontuadas por meio de tabelas de nível de competências, em uma escala de 1 a 5 (tabela 1). 
Tabela 1. Competências: média geral

\begin{tabular}{lrrrrrrrrrr}
\hline Competências & \multicolumn{10}{c}{ Participantes } \\
\cline { 2 - 11 } & $\mathbf{1}$ & $\mathbf{2}$ & $\mathbf{3}$ & $\mathbf{4}$ & $\mathbf{5}$ & $\mathbf{6}$ & $\mathbf{7}$ & $\mathbf{8}$ & $\mathbf{9}$ & $\mathbf{1 0}$ \\
\hline Texto & 5 & 5 & 2,8 & 5 & 3,2 & 3,7 & 5 & 5 & 3 & 2,7 \\
Imagem & 5 & 5 & 2,9 & 2,8 & 2,8 & 4,5 & 5 & 5 & 4,1 & 3,4 \\
Fotografia & 4,6 & 4,7 & 4,3 & 4,4 & 3,5 & 3,7 & 4,3 & 4,7 & 3,8 & 3,9 \\
Vídeo & 4,9 & 4,7 & 4,4 & 4,7 & 3,6 & 4,2 & 4,3 & 4,8 & 3,6 & 4,8 \\
Média Geral & 4,875 & 4,85 & 3,6 & 4,225 & 3,275 & 4,025 & 4,65 & 4,875 & 3,625 & 3,7 \\
\hline
\end{tabular}

Fonte: Elaboração própria.

A partir desse diagnóstico, o conjunto de participantes foi subdividido em grupos, reunindo usuários com competências distintas. Assim, cada um pôde aprender com o outro, reiterando o processo de 'Translação do Conhecimento'. Além disso, a mediadora pôde saber exatamente as competências que cada participante possuía e quais deveriam ser desenvolvidas para a produção do blog.

Outro resultado do projeto está relacionado com o processo de construção do blog, que foi feito após finalizar a etapa de diagnóstico e nivelamento. Em um primeiro momento, foram realizadas atividades buscando criar intimidade entre os participantes e a construção de um blog comunitário, ou seja, um ambiente virtual que traduza impressões, visões e experiências de pessoas, residentes em comunidades de baixa renda, que vivem em sofrimento psíquico, reiterando o protagonismo desses atores na comunicação da sua própria experiência.

Para tanto, os participantes foram convidados a conhecer alguns sites elaborados e voltados por e para moradores de favelas e regiões periféricas, como a 'Voz das comunidades'16 e o 'Fala Manguinhos'17, e outros construídos por cidadãos com determinadas patologias, como o 'Memórias de um esquizofrênico'18, 'Diário câncer de mama'19 e 'Viver em Depressão'20. A mediadora orientou os participantes a observar e avaliar esses blog e sites para identificar os aspectos visuais, de usabilidade e de compreensão do texto que poderiam ser aproveitados no blog que iriam construir coletivamente. Essas atividades tinham também o objetivo despertar o senso crítico do papel das mídias digitais no contexto contemporâneo.

Por meio de debates e atividades práticas, os participantes constataram o potencial do blog para mostrar a realidade das comunidades e produzir uma comunicação de moradores de comunidade para moradores. Além disso, foi ressaltada a importância de um veículo de comunicação entre usuários de Caps e a comunidade.

Depois de examinar algumas iniciativas existentes, os participantes decidiram que todos os conteúdos postados deveriam ser assinados pelo(a/s) autor(a/s). Um aspecto de destaque é a escolha por um foco ampliado de temas, e não restritos a sintomas, doença e formas de tratamento. Seria um blog que revelasse esperança, arte, piada, música, ou seja, formas como esses participantes compreendem o viver a vida, e não apenas tragédia, dor e sofrimento. Depois de intenso debate, eles escolheram o nome do blog: 'Libertando a Mente'21. Segundo os participantes, esse nome foi escolhido por não reiterar o estigma do qual são vítimas. Eles também decidiram o texto que deveria constar nas seções 'Quem somos' e 'Sobre'. Na oportunidade, cada participante passou a ser responsável por redigir um texto com, no máximo, cinco linhas sobre 
si, informando onde morava, o que gostava de fazer e qual era a expectativa que cada um tinha com o blog. Cada um escolheu uma fotografia que passou a constar no seu respectivo perfil. Eles também escolheram a imagem de capa. Para isso, foi feito um debate acerca de quais conceitos poderiam ser ilustrados por meio de uma imagem e o que significa liberdade para os participantes, já que a palavra foi escolhida para o nome do blog.

Entre as sugestões, aquela com maior aceitação entre os participantes foi a de liberdade enquanto portas abertas, o direito de circular e acessar espaços. A partir da expressão 'portas abertas', foi feita uma busca no Google Imagens. Assim, foi escolhida uma imagem que apresenta a porta aberta para um céu azul. Após esse processo, os participantes passaram a realizar reuniões de pauta com a mediadora em que cada usuário sugeria algum tema para ser abordado e disponibilizado no blog e o formato adotado. Um cronograma de atividades foi criado pelo grupo que definia o tempo de produção e as datas de apresentação, revisão e postagem de cada conteúdo. Este visava não só garantir que o blog tivesse uma produção contínua, mas também gerasse um sentimento nos participantes como responsáveis pela sua atualização naquele dia específico. Esse processo, progressivamente, foi adotado como rotina entre o grupo que produzia o cronograma com atividades, divisão de responsabilidades e produção de conteúdo. Em alguns casos, as duplas eram orientadas a trabalhar durante a semana fora do laboratório, realizando entrevistas, filmagens e fotografias em outros espaços; para, só então, retornar com o material coletado, utilizando o computador para escrita e edição dos conteúdos. Cada dupla tinha um período estabelecido no cronograma para a realização de suas atividades.

Com o conteúdo preliminar pronto, cada dupla fazia uma apresentação do material (vídeo, foto, texto) para os demais participantes do projeto na sala do LaISS, fazendo comentários sobre seu processo de produção. Depois que a exposição se encerrava, iniciava-se um debate em que os demais participantes opinavam, expondo discordâncias, concordâncias e sugestões. Assim, essas apresentações se tornaram momentos de troca de experiências, já que, por diversas vezes, produziam não só debate sobre a forma como o conteúdo estava apresentado, mas também sobre o tema, abrindo espaço para que outros participantes trouxessem suas vivências e experiências. Feita a apresentação e ouvidas as sugestões e críticas, cada dupla voltava a trabalhar o conteúdo previsto, fazendo correções ou alterações sugeridas, que poderiam acontecer no mesmo dia ou nas semanas seguintes. Nesse processo de produção de conteúdo, a mediadora procurava interferir o mínimo possível.

À medida que os conteúdos iam sendo concluídos, iniciava-se o processo de inserção no ambiente virtual. Essa etapa do trabalho também foi protagonizada pelos participantes do projeto. Ela foi iniciada depois que todos os participantes já se conheciam, e a mediadora havia identificado um participante que havia demonstrado mais facilidade no lidar com as ferramentas tecnológicas digitais. Assim, um dos participantes foi escolhido e se prontificou a exercer a função de inserir o produto no ambiente virtual. Ele passou a utilizar o computador principal da sala do LaISS, que ficava ligado ao projetor, para que todos pudessem acompanhar o passo a passo de cada postagem. Essa atividade, portanto, contou com a participação de todos, apesar de ter sido executada por um único participante. O mesmo ocorreu na definição de tags e categorias, que servem como agrupadores, organizando o conteúdo e facilitando pesquisas, tanto no YouTube quanto no WordPress. Os usuários eram encorajados a pensar de que forma aquela postagem se relacionava com outros conteúdos e temas do blog e como os visitantes poderiam chegar até o conteúdo postado nele. Com o tempo e a maior intimidade com a tecnologia, outros participantes passaram a realizar a postagem do conteúdo.

No dia 27 de agosto de 2019, foi realizada a sessão de lançamento do blog no Salão Internacional da Ensp/Fiocruz. A sessão foi 
dividida em dois momentos. No primeiro, os protagonistas do processo leram um texto produzido por eles coletivamente. Em um determinado momento do texto, eles afirmaram que:

Todo início é difícil... sem saber o que estaria por vir aceitamos a responsabilidade de realizar esse blog, cada um teve seu momento de dificuldade, uns na escrita, outros nas fotos, alguns nos vídeos ou no conteúdo das postagens. Entretanto, em todos os momentos, procuramos nos superar com a ajuda uns dos outros usando o que aprendemos durante esse processo $^{\mathbf{2 2}}$.

Em seguida, foi formada uma mesa composta pelo professor Paulo Amarante, autoridade nacional sobre a RPB, pela professora Inesita Araújo, especialista em comunicação e saúde, e pelo médico Hugo Fernandes - então superintendente de saúde mental da Secretaria Municipal de Saúde do Rio de Janeiro.

Em uma atividade realizada após o evento, um participante fez o seguinte comentário sobre a cerimônia de lançamento de blog:

Me senti muito orgulhoso do trabalho feito por mim e a equipe. Foi um dia emocionante, compartilhamos juntos neste dia, o melhor do nosso afeto e ver o nosso trabalho feito e amplificado ${ }^{23}$.

A nosso ver, o projeto atendeu seu objetivo, pois foi capaz de promover a inclusão digital dessa população tradicionalmente excluída e ainda conseguir com que ela produzisse um blog - promovendo a comunicação dos usuários em redes sociais pessoais e o uso da internet de forma autônoma. Ele também permitiu a aproximação entre usuários, construindo espaços de diálogo entre estes, seus familiares e a sociedade, além de ajudar a construir uma nova relação desses indivíduos com o território. Essas relações se apresentavam de forma direta, como o aumento da circulação no território, o sentimento de pertencimento a um projeto, a ampliação da relação de cooperação e solidariedade, o sentimento de autoconfiança quanto às conquistas obtidas com o blog $\mathrm{e}$ seu reconhecimento público; no entanto, de modo indireto, como mediante publicização de temas por meio dos quais criavam canal de comunicação com a sociedade.

\section{Conclusões}

A RPB se configura como um processo voltado para a transformação do paradigma de cuidado em saúde mental. Ao olhar para o sujeito em sofrimento, e não para a doença, a experiência insere esse cidadão em um contexto de necessidades concretas e subjetivas nas diversas perspectivas de sua existência. Amarante ${ }^{24}$ discorre sobre as quatro dimensões da RPB como teórico-conceitual, jurídico-político, técnico-assistencial e sociocultural. Nesse sentido, a seu ver, a RPB não se limita ao âmbito da saúde. Sua proposta visa resgatar a cidadania. Nesse caso, a diversidade e o pertencimento tornaram-se conceitos fundamentais nesse percurso. Ao longo de quatro décadas, a RPB se constituiu uma política de Estado por meio de um arcabouço jurídico amplo e de ações intersetoriais. $\mathrm{O}$ fechamento progressivo de leitos e hospitais psiquiátricos, em paralelo ao crescimento exponencial de dispositivos de cuidado em liberdade - como os Caps -, apesar de ainda insuficientes em sua distribuição pelo Brasil, possibilitaram a milhares de usuários desses serviços a preservação de vínculos que antes eram rompidos pelas longas e frequentes internações hospitalares.

No entanto, tais avanços também trouxeram novos desafios. O cuidado em liberdade na cidade trouxe em seu bojo a premência de desconstruir os estigmas de incapacidade e periculosidade atribuídos à loucura. Essa modalidade de atenção exige o enfrentamento de aspectos socioculturais como o imaginário acima descrito e outros ligados às condições de vulnerabilidade e exclusão. Nesse sentido, é fundamental a incorporação de estratégias para além da reorganização de serviços. Com 
os avanços tecnológicos da sociedade, a construção do protagonismo das pessoas em sofrimento psíquico e dos usuários dos dispositivos em saúde mental exige a incorporação de novas ferramentas que possibilitem a interlocução ampliada com diversos atores sociais, além de potencializar suas habilidades em seus modos de andar a vida. $\mathrm{O}$ advento da internet e seus usos podem hoje ser um importante agregador para a superação desses novos desafios.

Ao avaliar essa iniciativa, é possível identificar alguns fatores que facilitaram ou dificultaram sua plena realização. Foram identificados quatro fatores que facilitaram a realização do projeto.

O primeiro deles foi a utilização da metodologia da 'Translação do Conhecimento'. Por intermédio das trocas de conhecimento e vivências proporcionadas pelo método os encontros realizados no LaISS, constituíram espaços confiáveis para o exercício de fala. Os usuários puderam se expressar livremente, tendo oportunidade de aprender e ensinar uns aos outros e construir coletivamente o blog trocando experiências.

Um segundo fator facilitador está relacionado com o fato de a atividade ter sido realizada fora do espaço do Caps. A necessidade de transitar por um novo espaço ajudou na promoção da autonomia dos participantes e serviu como um incentivo à integração do grupo, já que, muitas vezes, eles se deslocavam em conjunto. A circulação dos usuários se mostrou como um facilitador na emancipação desses cidadãos.

Um terceiro elemento que facilitou essa atividade está relacionado com o fato de ela ter sido realizada nas dependências do LaISS: uma sala equipada com dez computadores, ligados à internet, datashow e ar-condicionado. Assim, não foi necessária a constituição da infraestrutura tecnológica necessária para a realização da atividade. Além disso, esse projeto havia sido aprovado em um edital de Divulgação Cientifica da Vice-Presidência de Ensino, Informação e Comunicação da Fiocruz. Essa aprovação permitiu que os usuários recebessem uma bolsa que contribuiu para o aumento da autoestima e favoreceu a adesão dos participantes.
O último fator facilitador identificado foi o perfil dos participantes. Como já foi exposto, os usuários selecionados para a participação no projeto eram, em sua maioria, jovens adultos com conhecimento básico necessário para utilização da NTIC. Esse perfil fez com que não fossem necessários muitos encontros e atividades voltadas para a formação técnica dos participantes, tornando o trabalho mais rápido de produtivo. Foi possível iniciar a etapa de produção de conteúdo em menos tempo do que seria possível com um grupo com pessoas mais idosas ou sem o mesmo domínio das tecnologias.

Consideramos que dois fatores dificultaram a realização do projeto. $O$ primeiro deles foi a violência que domina o território de Manguinhos, onde ocorrem constantes conflitos armados entre a milícia, a polícia e os traficantes de droga. Durante todo o período de realização do projeto, quatro encontros não foram realizados em função de tiroteios na região. Eles colocaram participantes e equipe em risco impedindo o deslocamento de todos até o LaISS. Algumas vezes, esses conflitos armados foram noticiados na imprensa. O segundo fator que dificultou a plena realização da atividade foram os efeitos colaterais dos medicamentos psicotrópicos consumidos pelos usuários. Muitas vezes, alguns chegavam à sala do LaISS sob o efeito dessas medicações, apresentando sonolência ou dificuldade de concentração nas atividades propostas. Isso implicou a necessidade de pensar didáticas diferenciadas que proporcionassem um maior envolvimento.

Dois desafios merecem ser analisados se houver interesse em replicar essa experiência em outros ambientes. Em primeiro lugar, constatamos que houve um engajamento desigual dos usuários. Aproximadamente a metade dos usuários foi proativa, envolvendo-se e tomando frente de ações. A outra metade se envolveu pouco e não mostrou interesse nas atividades. Esse segundo grupo se mostrou interessado, sobretudo, em receber a bolsa. No contexto de vulnerabilidade da população-alvo, a 
valorização da participação por incentivo financeiro não necessariamente é negativa, mas precisa ser acompanhada de uma ressignificação do processo como agregador de ferramentas de protagonismo e emancipação. Outro desafio está relacionado com a construção de narrativas que não sejam centradas apenas na dor e no sofrimento. A emancipação dos usuários foi pensada a partir da perspectiva sociocultural da RPB. Nesse sentido, buscamos encorajar os participantes a se afastarem da condição de doente mental. Sugerimos que esta não fosse a principal temática e/ou única. Incentivamos os participantes a valorizar a criatividade e as afinidades existentes entre eles. Assim, foram surgindo temas referentes a arte, esporte e alimentação. Nesse ponto, a formação do pensamento crítico e a mediação baseada na 'Translação do Conhecimento' se mostraram muito importantes para ampliar a visão dos participantes.

A sustentabilidade do blog se mostrou como um desafio de natureza prática. O projeto não encontrou uma solução para tornar sua produção rentável.

Por fim, é desafiador pensar a viabilidade tecnológica de ações dessa natureza em outros espaços. O projeto se tornou possível por meio de uma estrutura técnica que não é a realidade da maioria dos dispositivos da Raps. Isso pode ser um limitador, impedindo que projetos semelhantes ocorram. Parcerias entre dispositivos de saúde mental e instituições de outras naturezas e o investimento em laboratórios de informática são alternativas que podem contribuir para o enfrentamento desse problema.

As NTIC engendram inúmeras possibilidades de criação e transformação para diferentes áreas da sociedade, incluindo o campo da saúde mental. Neste artigo, relatamos os resultados de um projeto de inclusão digital e social realizado com um grupo de usuários atendidos pelo Caps-Magal, em Manguinhos. Entretanto, cabe ressaltar que outras iniciativas já foram realizadas nessa área, dentre as quais, destacam-se: a experiência do 'Oficinando em Rede'25 em
Porto Alegre, e aquela relatada por Bittencourt, Francisco e Mercado ${ }^{26}$ em Sergipe.

Nosso projeto se assemelha com esses dois, pois buscou estabelecer uma parceria com a Raps que encaminhou os participantes e, também, realizou oficinas que incrementaram a autonomia e o protagonismo dos sujeitos. Entretanto, alguns aspectos singularizaram a experiência descrita neste artigo em relação às experiências anteriores.

O fato de a atividade ter sido realizada uma vez por semana durante 12 meses contribuiu para que laços mais sólidos fossem estabelecidos entre os usuários. Alguns deles, que não possuíam uma relação anterior, passaram a fazer parte do círculo social uns dos outros, realizando atividades em conjunto fora do projeto, ampliando suas redes de sociabilidade. Além disso, conforme os participantes se apropriaram do processo, o papel da mediadora decresceu. Eles passaram a ter mais facilidade e autonomia para realizar as atividades sem supervisão e expandiram sua atuação para fora do laboratório, trazendo sugestões de casa e produzindo conteúdo em outros ambientes.

Lupton ${ }^{27}$ entende que as populações excluídas têm menores condições de se beneficiar com o uso das NTIC, pois seu domínio sobre hardwares e softwares é muito limitado. Cabe salientar que a experiência apresentada e analisada neste artigo chegou a uma conclusão diferente. Os 10 usuários do Caps-Magal que participaram deste projeto integram um perfil etário jovem, pois tinham entre 20 e 40 anos. A maior parte do grupo relatou intimidade com a internet e com as ferramentas digitais: 8 participantes possuíam e-mail, e todos possuíam Facebook. Vários deles tinham como passatempo os videogames. Ao longo do processo, eles revelaram ter competência suficiente para o manuseio dessas NTIC. Outros aprenderam a utilizá-las com o auxílio e orientação dos colegas.

A partir dessa experiência, é possível pensar novas possibilidades para o desenvolvimento de processos comunicacionais e de produção de conteúdo na Raps - questões que ainda são muito pouco tratadas. O referencial teórico da 
*Orcid (Open Researcher and Contributor ID).
‘Translação do Conhecimento' e a abordagem pedagógica de Paulo Freire aplicados à comunicação, mais especificamente ao uso das NTIC e à inclusão digital, mostraram-se efetivos em produzir um ambiente terapêutico de aprendizagem, que promoveu a emancipação dos usuários por meio da troca de conhecimento, da autonomia e da autocrítica.

Este artigo apresenta e analisa uma modesta contribuição sobre o uso das NTIC como instrumento facilitador da autonomia e visibilidade dos cidadãos em sofrimento psíquico. Esperamos que ela sirva de inspiração para outras iniciativas semelhantes.

\section{Referências}

1. Pereira Neto A, Flynn M. The Internet and health in Brazil: trends and challenges. In: Pereira Neto A, Flynn M, organizadores. The Internet and health in Brazil: trends and challenges in Brazil. Cham: Springer; 2019. p. 1-14.

2. Castells M, Himanen P. Reconceptualizing development in the global information age. Oxford: Oxford University Press; 2014.

3. Harris AL, Rea A. Web 2.0 and Virtual World Technologies: A Growing Impact on IS Education. J. Info. Syst. Edu. 2009; 20(2):137-144.

4. International Telecommunication Union. Measuring the Information Society Report 2007 [internet]. [acesso em 2020 ago 15]. Disponível em: https://www.itu. int/en/ITU-D/Statistics/Pages/publications/mis2007. aspx.

\section{Colaboradores}

Pereira Neto A (0000-0003-3631-8857)* Ribeiro BD (0000-0003-2208-1270)*, Guljor APF (0000-0003-1952-6064)*, Barbosa L (0000-0002-7341-260X)*, Sampaio CMA (0000-0003-3038-1695)*, Castro CA (00000002-0769-9008)* e Amarante P (00000001-6778-2834)* colaboraram igualmente para concepção e planejamento da pesquisa; para análise e interpretação dos dados e para redação e aprovação da versão final do manuscrito.
5. International Telecommunication Union. Measuring the Information Society Report 2018. vol 1 [internet]. Geneva: ITU; 2018. [acesso em 2020 ago 15]. Disponível em: https://www.itu.int/en/ITU-D/Statistics/ Documents/publications/misr2018/MISR-2018-Vol1-E.pdf.

6. Ragnedda M. The third digital divide: A weberian approach to digital inequalities. New York: Routledge; 2017.

7. Gutiérrez LH, Gamboa LF. Determinants of ICT usage among low-income groups in Colombia, Mexico, and Peru. The Info. Soc. 2010; 26(5):346-363.

8. Garcia PT, Reis RMS. Redes de atenção à saúde: Rede de Atenção Psicossocial - RAPS. São Luís: Edufma; 2018. 
9. Amarante P, Nunes MO. A reforma psiquiátrica no SUS e a luta por uma sociedade sem manicômios. Ciênc. Saúde Colet. 2018; 23(6):2067-2074.

10. Oliveira VC, Capistrano FC, Ferreira ACZ, et al. Perfil sociodemográfico e clínico de pessoas atendidas em um Caps ad do sul do brasil. Rev. baiana enferm. 2017; 31(1):e16350.

11. Pereira Neto A, Barbosa L, Barão L, et al. Digital Natives and Health: An Exploratory Study with Young Brazilians of Different Socioeconomic Profiles. In: Pereira Neto A, Flynn M, organizadores. The Internet and Health in Brazil. Challenges and Trends. Cham: Springer; 2019. p. 113-140.

12. Clavier C, Sénéchal Y, Vibert S, et al. A theory-based model of translation practices in public health participatory research. Sociology of Health \& Illness. 2011; 34(5):791-805.

13. Mantoura P, Gendron S, Potvin L. Participatory research in public health: Creating innovative alliances for health. Health Place. 2007; 13:440-451.

14. Freire P. A pedagogia do oprimido. Rio de Janeiro: Paz e Terra; 1987.

15. Sacristán JC, Gómez AIP, Rodríguez JBM, et al. Educar por competências: o que há de novo? São Paulo: Artmed; 2011.

16. Voz das Comunidades. Início [internet]. [acesso em 2020 fev 29]. Disponível em: http://www.vozdascomunidades.com.br/.

17. Fala Maguinhos. Início [internet]. [acesso em 2019 jun 30]. Disponível em: http://www.falamanguinhos. com.br/.

18. Memórias de um esquizofrênico [internet]. [acesso em 2020 fev 29]. Disponível em: https://memoriasdeumesquizofrenico.blogspot.com/.
19. Diário Câncer de Mama [internet]. [acesso em 2020 fev 29]. Disponível em: https://diariocancerdemama. blogspot.com/.

20. Viver com depressão [internet]. [acesso em $2020 \mathrm{fev}$ 29]. Disponível em: http://vivercomdepressao.blogspot.com/.

21. Libertando a mente [internet]. [acesso em $2020 \mathrm{fev}$ 29]. Disponível em: https://projetolibertandoamente.wordpress.com.

22. Fundação Oswaldo Cruz. Ceensp Libertando a Mente - mesa de abertura [internet]. [acesso em 2020 ago 15]. Disponível em: https://portal.fiocruz.br/video/ ceensp-libertando-mente-mesa-de-abertura.

23. Projeto Libertando a Mente. Lançamento do blog libertando a mente nossos relatos [acesso em 2020 ago 15]. Disponível em: https://projetolibertandoamente. wordpress.com/2019/09/02/lancamento-do-blog-libertando-a-mente-nossos-relatos/.

24. Amarante P. A (clínica) e a Reforma Psiquiátrica. In: Amarante P, organizador. Arquivos de Saúde Mental e Atenção Psicossocial. Rio de Janeiro: Nau; 2003. p. 45-65.

25. Maraschin C, Francisco DJ, Diehl R, organizadores. Oficinando em rede: oficinas, tecnologias e saúde mental. Porto Alegre: UFRGS; 2011.

26. Bittencourt IGS, Francisco DJ, Mercado LPL. Autoria em blog por pessoas em sofrimento psíquico: aprendizagem compartilhada, reconhecimento e promoção da saúde mental. Psicol. cienc. prof. 2013; 33(4):988999.

27. Lupton D. Digital Sociology. London: Routledge; 2015.

Recebido em 02/03/2020

Aprovado em 25/08/2020

Conflito de interesses: inexistente

Suporte financeiro: não houve 